\title{
Tempestade de citocinas e desenvolvimento de doenças autoimunes como sequela da
}

\section{Covid-19}

\author{
Cytokine storm and development of autoimmune diseases as a sequel of Covid-19 \\ Tormenta de citocinas y desarrollo de enfermidades autoimunes como secuela de Covid-19
}

Recebido: 12/08/2021 | Revisado: 17/08/2021 | Aceito: 18/08/2021 | Publicado: 22/08/2021

Bárbara Queiroz de Figueiredo

ORCID: https://orcid.org/0000-0003-1630-4597 Centro Universitário de Patos de Minas, Brasil

E-mail: barbarafigueiredo@unipam.edu.br

Ana Paula Ferreira Araújo

ORCID: https://orcid.org/0000-0002-6998-7558

Centro Universitário de Patos de Minas, Brasil

E-mail: anapfaraujo@unipam.edu.br

Carlos Daniel Silva

ORCID: https://orcid.org/0000-0002-7997-5155

Centro Universitário de Patos de Minas, Brasil

E-mail: carlosdanie18613@gmail.com

Diego Arthur Castro Cabral

ORCID: https://orcid.org/0000-0002-7582-7251

Universidade Federal do Pará, Brasil

E-mail: diego.arthur.castro@gmail.com

Gardênia Silva Amorim

ORCID: https://orcid.org/0000-0001-7888-8562

Centro Universitário de Atenas, Brasil

E-mail: gardênia.sa@hotmail.com

Gustavo Alves Medeiros

ORCID: https://orcid.org/0000-0002-6732-0258

Centro Universitário de Atenas, Brasil

E-mail: gustapo13m@gmail.com

Isadora Queiroz Presot

ORCID: https://orcid.org/0000-0003-1117-1211

Centro Universitário Euroamericano, Brasil

E-mail: presotisadora@gmail.com

Júlia de Mendonça Queiroz

ORCID: https://orcid.org/0000-0002-5856-3901

Centro Universitário de Patos de Minas, Brasil

E-mail: juliamendoncaqueiroz@gmail.com

Luana Damaceno Miranda

ORCID: https://orcid.org/0000-0003-4013-2414

Centro Universitário de Patos de Minas, Brasil

E-mail: luanad.m@hotmail.com

Maria Paula Pereira Lessa

ORCID: https://orcid.org/0000-0001-8587-3625

Centro Universitário Atenas, Brasil

E-mail: mariapaulalessa@gmail.com

Vinícius Slonski Delboni

ORCID: https://orcid.org/0000-0003-2455-3753

Centro Universitário de Patos de Minas, Brasil

E-mail: viniciusdelboni@unipam.edu.br

\section{Resumo}

Introdução: Pesquisadores da Universidade de Rockefeller, em Nova York, encontraram em alguns doentes graves por Covid-19 um tipo de autoanticorpo que ataca outras células do sistema imunológico. Para os cientistas, isso seria um indício de que esses pacientes tinham autoanticorpos preexistentes à doença e que esse seria o motivo pelo qual desenvolveram a forma grave da Covid-19. Objetivo: Responder quais as evidências sobre a infecção por Sars-CoV-2 e desencadeamento de autoimunidade. Metodologia: Trata-se de uma pesquisa descritiva do tipo revisão integrativa da literatura, que buscou responder quais as evidências sobre a infecção por Sars-CoV-2 e desencadeamento de autoimunidade. A pesquisa foi realizada através do acesso online nas bases de dados National Library of Medicine (PubMed MEDLINE), Scientific Electronic Library Online (Scielo), Cochrane Database of Systematic Reviews (CDSR), Google Scholar, Biblioteca Virtual em Saúde (BVS) e EBSCO Information Services, no mês de julho de 2021. Resultados: Acredita-se que o Covid-19 possua características clínicas semelhantes às doenças autoimunes, pois 
ambas compartilham grandes reações imunes da patogênese. Relatos de caso de pacientes que desenvolveram síndrome de Guillain-Barré, anemia hemolítica autoimune e lúpus eritematoso sistêmico foram expostos. Conclusão: O Sars-CoV-2 pode alterar a autotolerância e gerar respostas autoimunes através da reatividade cruzada com células hospedeiras. No entanto, ficará a cargo da comunidade científica investigar essa possibilidade mais a fundo para validar ou reprovar essa hipótese, haja vista a facilidade em detectar autoanticorpos, corroborando, dessa forma, a constatação de que eles, desencadeados ou não pela Covid-19, são realmente uma ameaça de alteração no sistema imunológico.

Palavras-chave: Covid-19; Autoimunidade; Citocinas; Sistema imunológico.

\begin{abstract}
Introduction: Researchers at Rockefeller University, New York, found in some seriously ill patients with Covid-19 a type of autoantibody that attacks other cells of the immune system. For scientists, this would be an indication that these patients had preexisting autoantibodies to the disease and that this would be the reason why they developed the severe form of Covid-19. Objective: Answer what is the evidence on the infection by Sars-CoV-2 and triggering of autoimmunity. Methodology: This is a descriptive research of the integrative literature review type, which sought to answer what is the evidence on Sars-CoV-2 infection and triggering of autoimmunity. The search was carried out through online access in the National Library of Medicine (PubMed MEDLINE), Scientific Electronic Library Online (Scielo), Cochrane Database of Systematic Reviews (CDSR), Google Scholar, Virtual Health Library (BVS) and EBSCO databases Information Services, July 2021. Results: It is believed that Covid-19 has clinical characteristics similar to autoimmune diseases, as both share major immune responses of pathogenesis. Case reports of patients who developed Guillain-Barré syndrome, autoimmune hemolytic anemia and systemic lupus erythematosus were presented. Conclusion: Sars-CoV-2 can alter self-tolerance and generate autoimmune responses through crossreactivity with host cells. However, it will be up to the scientific community to investigate this possibility further to validate or disprove this hypothesis, given the ease of detecting autoantibodies, thus corroborating the finding that they, triggered or not by Covid-19, are really a threat of alteration in the immune system.
\end{abstract}

Keywords: Covid-19; Autoimmunity; Cytokines; Immune system.

\title{
Resumen
}

Introducción: Investigadores de la Universidad Rockefeller, Nueva York, han encontrado en algunos pacientes gravemente enfermos con Covid-19 un tipo de autoanticuerpo que ataca a otras células del sistema inmunológico. Para los científicos, esto sería una indicación de que estos pacientes tenían autoanticuerpos preexistentes contra la enfermedad y que esta sería la razón por la que desarrollaron la forma severa de Covid-19. Objetivo: Responder cuál es la evidencia sobre la infección por Sars-CoV-2 y desencadenamiento de autoinmunidad. Metodología: Se trata de una investigación descriptiva del tipo revisión integradora de la literatura, que buscó dar respuesta a cuál es la evidencia sobre la infección por Sars-CoV-2 y el desencadenamiento de autoinmunidad. La búsqueda se realizó a través del acceso online en la Biblioteca Nacional de Medicina (PubMed MEDLINE), Scientific Electronic Library Online (Scielo), Cochrane Database of Systematic Reviews (CDSR), Google Scholar, Virtual Health Library (BVS) y bases de datos EBSCO Information Services, Julio de 2021. Resultados: Se cree que Covid-19 tiene características clínicas similares a las enfermedades autoinmunes, ya que ambas comparten las principales respuestas inmunitarias de patogénesis. Se presentaron informes de casos de pacientes que desarrollaron síndrome de Guillain-Barré, anemia hemolítica autoinmune y lupus eritematoso sistémico. Conclusión: Sars-CoV-2 puede alterar la auto-tolerancia y generar respuestas autoinmunes a través de reactividad cruzada con células huésped. Sin embargo, corresponderá a la comunidad científica investigar más a fondo esta posibilidad para validar o refutar esta hipótesis, dada la facilidad para detectar autoanticuerpos, corroborando así el hallazgo de que, desencadenados o no por Covid-19, son realmente una amenaza de alteración. en el sistema inmunológico.

Palabras clave: Covid-19; Autoinmunidad; Citocinas; Sistema inmunológico.

\section{Introdução}

Pesquisadores da Universidade de Rockefeller, em Nova York, encontraram em alguns doentes graves por Covid-19 um tipo de autoanticorpo que ataca outras células do sistema imunológico. Para os cientistas, isso seria um indício de que esses pacientes tinham autoanticorpos preexistentes à doença e que esse seria o motivo pelo qual desenvolveram a forma grave da Covid-19. As análises sanguíneas foram feitas entre março e abril de 2021 e os resultados foram inusitados: ao invés de encontrar o mesmo autoanticorpo da pesquisa de Nova York, o pesquisador se deparou com uma variedade de 15 tipos de autoanticorpos prontos para atacar outras proteínas humanas, incluindo aquelas presentes em órgãos vitais e corrente sanguínea

(Chang, et al., 2021). 
Os autoanticorpos foram identificados em aproximadamente 50\% dos pacientes. Quando presentes, os autoanticorpos visam amplamente os autoantígenos associados a doenças raras, como miosite e esclerose sistêmica. Anticorpos antinucleares (ANA) foram observados em cerca de $25 \%$ dos pacientes. Os pacientes com autoanticorpos tendem a demonstrar uma ou algumas especificidades, enquanto os autoanticorpos são ainda mais prevalentes, e os pacientes costumam apresentar anticorpos para várias citocinas. Essas células imunológicas enlouquecidas apareceram no estudo em níveis altíssimos, variadas e onipresentes. Em alguns pacientes, as células imunológicas defeituosas estavam marcando células sanguíneas para atacar. Outras estavam caçando proteínas associadas ao coração, fígado, sistema nervoso central e cérebro. O resultado indica a possibilidade de um problema sistêmico: pacientes estariam desencadeando a produção de uma enorme variedade de novos autoanticorpos em resposta à Covid-19, levando os corpos dessas pessoas a entrar em guerra consigo mesmos (Chang, et al., 2021).

Assim, os resultados do estudo levaram a vários achados importantes que fornecem informações adicionais sobre a patogênese do Covid-19. Na maioria dos indivíduos, apenas pequeno número de autoantígenos são direcionados, o que é mais consistente com uma perda esporádica de autotolerância do que com um aumento global na produção de autoanticorpos. Além disso, os autoanticorpos descobertos são encontrados em doenças do tecido conjuntivo relativamente raras que não são normalmente medidas em laboratórios clínicos, e alguns são considerados patogênicos. Ademais, foram identificados anticorpos que reconhecem proteínas não estruturais SARS-CoV-2 que se correlacionam positivamente com autoanticorpos. Finalmente, e talvez o mais importante, alguns autoanticorpos são desencadeados pela infecção por SARSCoV-2, sugerindo que Covid-19 grave pode quebrar a tolerância ao próprio (Chang, et al., 2021).

Além disso, muitos pacientes pós Covid-19 experienciam a chamada "tempestade de citocinas", que são várias proteínas diferentes, enviadas pelas células imunológicas e por outras células, que atuam como mensageiras do sistema imunológico, que ajudam a regular uma resposta contra um inimigo indesejado. O problema é que nesse ataque, as citocinas acabam atingindo células do próprio corpo, além do inimigo, e isso pode deixar sequelas. A reação é parecida com o que se vê em pessoas com doenças autoimunes, que levam uma vida repleta de dores e danos a órgãos vitais devido à autorreatividade. Esses autoanticorpos são claramente recém-adquiridos, e apareceram durante a infecção, que provocou a autoimunidade (Chang, et al., 2021). Visto isso, o objetivo deste estudo é analisar a possibilidade real de que esses autoanticorpos sejam criados pela infecção de Covid-19 e que possam durar a vida toda, bem como levantar algumas questões perturbadoras, como quais seriam as consequências para os pacientes que adquirem autoanticorpos e quanta destruição essas células poderiam causar.

\section{Metodologia}

Trata-se de uma pesquisa descritiva do tipo revisão integrativa da literatura, que buscou responder quais as evidências sobre a infecção por Sars-CoV-2 e desencadeamento de autoimunidade. A pesquisa foi realizada através do acesso online nas bases de dados National Library of Medicine (PubMed MEDLINE), Scientific Electronic Library Online (Scielo), Cochrane Database of Systematic Reviews (CDSR), Google Scholar, Biblioteca Virtual em Saúde (BVS) e EBSCO Information Services, no mês de julho de 2021. Para a busca das obras foram utilizadas as palavras-chaves presentes nos descritores em Ciências da Saúde (DeCS): em inglês: "Covid-19", "autoimmunity", "cytokines", "Guillain-Barré". em português: "Covid-19", "autoimunidade", "citocinas", "Guillain-Barré", e em espanhol: "Covid-19", "autoinmunidad", "citocinas", "Guillain-Barré".

Como critérios de inclusão, foram considerados artigos originais, que abordassem o tema pesquisado e permitissem acesso integral ao conteúdo do estudo, publicados no período de 2020 a 2021, em inglês, português e espanhol. O critério de exclusão foi imposto naqueles trabalhos que não estavam em inglês, português e espanhol que não tinham passado por processo de Peer-View e que não relacionassem infecção por Sars-CoV-2 e desencadeamento de autoimunidade. A estratégia 
de seleção dos artigos seguiu as seguintes etapas: busca nas bases de dados selecionadas; leitura dos títulos de todos os artigos encontrados e exclusão daqueles que não abordavam o assunto; leitura crítica dos resumos dos artigos e leitura na íntegra dos artigos selecionados nas etapas anteriores. Assim, totalizaram-se 17 artigos científicos para a revisão integrativa da literatura, com os descritores apresentados acima. Após esta seleção, filtraram-se por artigos dos últimos dois anos e por artigos em línguas portuguesa, inglesa e espanhola.

\section{Resultados e Discussão}

Após a seleção dos artigos por meio dos critérios de inclusão e de exclusão, elaborou-se um quadro (Quadro 1), contendo as principais informações sobre a relação entre infecção por Covid-19 e desencadeamento de autoimunidade.

Quadro 1: Estudos utilizados na Revisão Integrativa e achados principais.

\begin{tabular}{|c|c|c|}
\hline AUTOR & ANO & PRINCIPAIS ACHADOS \\
\hline Alberti, P., et al. & 2020 & $\begin{array}{l}\text { Os autores relatam uma possível correlação entre infecções agudas por Covid-19 e síndrome de } \\
\text { Guillain-Barré, uma condição que nos últimos anos tem sido associada a outras infecções emergentes, } \\
\text { como Zika Vírus. }\end{array}$ \\
\hline Sedaghat, Z., et al. & 2020 & $\begin{array}{l}\text { Não está claro se Covid-19 induz a produção de anticorpos contra gangliósidos específicos que } \\
\text { geralmente aparecem com certas formas de síndrome de Guillain-Barré. }\end{array}$ \\
\hline Huang, C., et al. & 2020 & $\begin{array}{l}\text { O Covid-19 estimula células inflamatórias e produz vários processos inflamatórios pela tempestade de } \\
\text { citocinas e, como resultado, cria processos imunomediados. }\end{array}$ \\
\hline Mao, L., et al. & 2020 & $\begin{array}{l}\text { Estudo relatou o caso de um paciente masculino de } 65 \text { anos com queixas de simetria aguda } \\
\text { progressiva quadriparesia ascendente. Duas semanas antes da hospitalização, o paciente teve tosse, } \\
\text { febre e RT-PCR foi relatado como positivo para infecção por Covid-19. O teste de eletrodiagnóstico } \\
\text { mostrou que o paciente tinha uma variante da síndrome de Guillain Barré. }\end{array}$ \\
\hline Toscano, G., et al. & 2020 & $\begin{array}{l}\text { Recentemente, houve vários relatos de síndrome de Guillain-Barré associada à infecção Covid-19. A } \\
\text { maioria dos casos de síndrome de Guillain-Barré relacionados ao Covid-19 apresentou início agudo de } \\
\text { quadriparesia arreflexa e eram idosos. }\end{array}$ \\
\hline Gupta, A., et al. & 2020 & $\begin{array}{l}\text { Pacientes com síndrome de Guillain-Barré relacionada à Covid-19 tinha uma doença grave com } \\
\text { insuficiência respiratória devido a pneumonia lobar e pneumonite intersticial, evidenciadas, por } \\
\text { tomografia, pela aparência de vidro fosco dos pulmões. O aumento da gravidade da doença também é } \\
\text { evidente a partir do estudo de eletrofisiologia. A maioria dos pacientes com síndrome de Guillain- } \\
\text { Barré relacionados à Covid-19 tinha polineuropatia axonal motora (AMAN) e polineuropatia sensorial } \\
\text { motora axonal (AMSAN). }\end{array}$ \\
\hline Rana, S., et al. & 2020 & $\begin{array}{l}\text { Relatou-se um caso de síndrome de Guillain-Barré que foi precedido de infecção por Covid-19, em } \\
\text { que os déficits foram caracterizados por quadriparesia, disestesias ardentes e } \\
\text { disautonomia. Curiosamente, o paciente não tinha a perda de cheiro e gosto que foi documentado em } \\
\text { muitos pacientes com Covid-19. Ele brevemente exigiu ventilação mecânica, que foi retirada com } \\
\text { sucesso depois de receber imunoglobulina intravenosa. }\end{array}$ \\
\hline Rumeileh, S. A., et al. & 2021 & $\begin{array}{l}\text { A maioria dos pacientes apresentou sintomas respiratórios ou sistêmicos e desenvolveram } \\
\text { manifestações de síndrome de Guillain-Barré após Covid-19. No entanto, casos assintomáticos para } \\
\text { Covid-19 também foram descritos. Pacientes com resultados menos favoráveis foram associados a } \\
\text { uma idade significativamente mais velha de acordo com descobertas anteriores sobre síndrome de } \\
\text { Guillain-Barré clássica e Covid-19. Assim, essa síndrome associada a Covid-19 parece compartilhar a } \\
\text { maioria dos recursos de SGB pós-infecciosa clássica e possivelmente os mesmos mecanismos } \\
\text { patogenéticos imunomediados. }\end{array}$ \\
\hline Chan, M., et al. & 2020 & $\begin{array}{l}\text { A infecção por SARS-CoV-2 pode causar síndrome de Guillain-Barré. A apresentação, diagnóstico e } \\
\text { tratamento para a síndrome induzido por SARS-CoV-2 em todo o mundo durante a presente pandemia } \\
\text { parecem variar. }\end{array}$ \\
\hline Caress, J. B., et al. & 2020 & $\begin{array}{l}\text { Apesar de vários relatos de casos de síndrome de Guillain-Barré associada à Covid-19, a prevalência } \\
\text { permanece obscura, pois a averiguação e os relatórios são irregulares, e o número total de pacientes } \\
\text { Covid-19 simultâneos não é conhecido. Também é possível que os casos de síndrome de Guillain- } \\
\text { Barré podem ter sido incorretamente atribuídos a neuromiopatias ou não diagnosticada, sob contexto } \\
\text { de grave doença. }\end{array}$ \\
\hline $\begin{array}{l}\text { Ferreira, H. H. F., et } \\
\text { al. }\end{array}$ & 2020 & $\begin{array}{l}\text { Diversas complicações hematológicas eliminadas na doença pelo Sars-Cov-2, especialmente os } \\
\text { distúrbios de coagulação, hemostasia e leucopenia. Contudo, poucos casos de anemias, especialmente } \\
\text { como anemias autoimunes hemolíticas, foram expostos. A etiologia da anemia hemolítica autoimune }\end{array}$ \\
\hline
\end{tabular}




\begin{tabular}{|l|c|l|}
\hline & & $\begin{array}{l}\text { pode ser idiopática ou secundária ao uso de drogas, doenças (especialmente lúpus), linfomas e } \\
\text { doenças, como as desencadeadas por Mycoplasma pneumoniae e vírus Epstein-Barr. Os casos } \\
\text { encontrados falam sobre pacientes que desenvolveram anemia hemolítica autoimune, com diferentes } \\
\text { comorbidades prévias, simultaneamente ao relato de infecção prévia por Covid-19. }\end{array}$ \\
\hline Nesr, G., et al. & 2020 & $\begin{array}{l}\text { Foi relatada a ocorrência de anemia autoimune hemolíticas e um aumento acentuado na contagem de } \\
\text { linfócitos em um paciente sob terapia intensiva no contexto de Covid-19 grave. }\end{array}$ \\
\hline $\begin{array}{l}\text { Renganathan, V., et } \\
\text { al. }\end{array}$ & 2021 & $\begin{array}{l}\text { A anemia hemolítica autoimune associada à Covid-19 foi relatada em nove casos, entre os quais cinco } \\
\text { tinham malignidade e um tinha trombocitopenia congênita. }\end{array}$ \\
\hline Bonometti, R., et al. & 2020 & $\begin{array}{l}\text { No momento não é possível definir uma associação entre achados imunológicos e sintomas } \\
\text { patológicos entre Covid-19 e doenças autoimunes, no entanto, este relato de caso descreveu o caso de } \\
\text { um paciente que, após o desenvolvimento da infecção por Covid-19, desenvolveu anticorpos } \\
\text { autoimunes que persistiram com o tempo mais do que a fase viral. Esses anticorpos podem ser } \\
\text { responsáveis pela clínica multipatológica demonstrada pelo relato de caso. }\end{array}$ \\
\hline Zhou, Y., et al. & 2020 & $\begin{array}{l}\text { Fenômenos autoimunes existem nas pessoas afetados pela Covid-19. No entanto, o desenvolvimento } \\
\text { de doenças reumatológicas, como lúpus eritematoso sistêmico, após a infecção por Covid-19 não está, } \\
\text { atualmente, completamente descrita na literatura }\end{array}$ \\
\hline Magagnoli, J., et al. & 2020 & $\begin{array}{l}\text { Estudo que acompanhou 52 pacientes com Covid-19 em estado grave e que precisaram receber } \\
\text { tratamento na UTI concluiu que nenhum deles tinha histórico de doenças autoimunes, mas mais da } \\
\text { metade deles foi detectado a presença de autoanticorpos. }\end{array}$ \\
\hline Batista, B. O., et al. & 2021 & $\begin{array}{l}\text { Há casos de indivíduos sem doenças autoimunes que manifestaram sinais clínicos da lúpus após a } \\
\text { infecção pelo vírus Sars-CoV-2. }\end{array}$ \\
\hline
\end{tabular}

Fonte: Autores (2021).

Os pesquisadores do estudo de Magagnoli et al. (2020) acreditam que essa constatação indica que essa reação do organismo pode estar ligada às formas mais graves da doença. Ademais, explicam que esse tipo de reação causada por uma infecção viral não é tão incomum, pois os vírus fazem as células morrerem, mas ocasionalmente elas acabam deixando uma área do DNA exposta. Enquanto isso, anticorpos funcionam reconhecendo o RNA viral e ligando-se ao vírus para impedir que ele invada as células. No entanto, em algumas situações, em vez de o sistema imunológico reconhecer o RNA, ele encontra o DNA do próprio corpo, expondo e produzindo uma resposta contra ele, fazendo com que anticorpos comecem a atacar o organismo.

\section{- Guillain-Barré}

Embora muito se saiba sobre as complicações respiratórias da infecção por Sars-CoV-2 com quadros agudos graves, como a síndrome respiratória, um espectro mais amplo de manifestações neurológicas começaramm a ser observadas (Chan, et al. 2020). Os poucos casos de GBS associados com outros coronavírus, incluindo a sinusite respiratória do Oriente Médio (MERS) demonstram que o mecanismo pós-infeccioso do GBS também é suportado pela descoberta de autoanticorpos que resultam de uma resposta imune dirigida a um epítopo do agente infeccioso que, então, apresenta reação cruzada com um componente estruturalmente semelhante do nervo periférico, resultando em lesão imunomediada retardada ao nervo periférico (Caress, et al. 2020)

A pandemia de Covid-19 leva a todos os esforços para a recuperação, diagnóstico e tratamento de suas manifestações. Em analogia a outros vírus, pertencentes ou não à família coronavírus, complicações neurológicas em Covid-19 estão emergindo como um dos capítulos clínicos mais significativos desta pandemia. A este respeito, danos aos nervos periféricos e centrais devido infecção por Covid-19 foram postulados como consequências de dois mecanismos diferentes: hematogenous (infecção de células endoteliais ou leucócitos) ou transneuronal (via trato olfatório ou outros nervos cranianos) e disseminação para o sistema nervoso central em relação ao vírus (neurotropismo) e resposta imunomediada anormal causando envolvimento neurológico secundário (Rumeileh, et al., 2021). 
Relato de caso apresentado por Alberti et al. (2020), em que um paciente, depois de recuperado da Covid-19, desenvolveu síndrome de Guillain-Barré, sugere que a Covid-19 pode causar envolvimento do sistema nervoso, mesmo antes da resolução da pneumonia, atendendo aos critérios diagnósticos de uma polirradiculoneurite motora. Além disso, a desregulação do sistema imunológico devido ao Covid-19 não é tão surpreendente devido descrição recente de hiperinflamação em pacientes com Covid-19 com uma síndrome de macrófagos ácidos, também conhecida como hemofagocítica secundária linfo-histiocitose.

Sintomas neurológicos associados à infecção por Covid-19 foram relatados por Mao et al. (2020), e também foram relatadas em outro beta coronavírus (SARS e MERS) que incluía polineuropatia, miopatia, AVC e GBS. Estudos sobre coronavírus têm foi demonstrado que esses vírus são neurotróficos, e embora estes estudados não tenham sido realizados sob o contexto de Covid-19, o arranjo de SARS e MERS, especialmente SARS, são muito semelhantes aos do Covid-19. Dessa maneira, o vírus se liga ao receptor da enzima de conversão 2 da angiotensina, que é detectado na membrana celular de numerosos órgãos humanos, incluindo pulmão, rim, fígado, sistema nervoso e músculo esquelético (Huang et al., 2020). O mecanismo de formação de GBS em pacientes infectado com Covid-19 ainda não foi totalmente investigado, mas sabe-se que a Covid-19 estimula as células inflamatórias e produz vários processos inflamatórios citocinas e, como resultado, cria processos imunomediados. Não está claro se Covid-19 induz o pro- produção de anticorpos contra gangliósidos específicos que geralmente aparecem com certas formas de síndrome de Guillain-Barré (Sedaghat, et al., 2020).

A polineuropatia na síndrome de Guillain-Barré acredita-se que seja devido à imunidade cruzada contra epítopos de componentes de nervos periféricos que ele compartilha com os epítopos na superfície celular das bactérias que produzem um antecedente da infecção (Toscano, et al. 2020). Este mecanismo de "mimetismo molecular" é melhor compreendido com a síndrome de Guillain-Barré relacionada com Campylobacter jejuni, que expressa vários antígenos gangliosídeos em seu núcleo externo. A infecção antecedente com $C$. jejuni resulta na formação de anticorpos contra gangliósidos presentes na membrana axonal. A presença destes anticorpos anti-gangliósidos a está fortemente associada a AMAN, AMSAN e variantes MillerFischer de síndrome de Guillain-Barré (Gupta, et al., 2020).

Comum aos casos relatados na literatura, os sintomas de síndrome de Guillain-Barré foram observados poucos dias após a infecção por Covid-19. Este início é semelhante a um relato de caso de zika agudo infecção de vírus com GBS simultâneo, sugerindo uma complicação parainfecciosa. Alguns relatos de caso demonstraram eletrofisiologia típica e achados de polineuropatia desmielinizante visto em pacientes com GBS, enquanto outros sugeriram que síndrome de Guillain-Barré está associada a COVID-19 são devidas às variantes axonais (Rana, et al. 2020).

\section{- Anemia Hemolítica Autoimune}

A anemia hemolítica autoimune é uma condição clínica na qual há produção do tipo IgG e/ou IgM contra antígenos de superfície das hemácias, culminando na destruição da via de ativação do sistema complemento e do sistema retículoendotelial. Pode ser primária ou idiopática, na qual a produção de tais imunoglobulinas podem ocorrer de forma idiopática, ou seja, sem associação evidente com outras doenças ou condições clínicas, e secundária - na qual o fenômeno imunológico está associado a neoplasias ou doenças reumatológicas. Sua refratariedade, marcada pela persistência de hemólise e hemoglobina abaixo de $10 \mathrm{~g} / \mathrm{dL}$ na vigência do tratamento, é fator preponderante antes da definição da abordagem, considerando sua relação com o prognóstico da doença e atentando para condições secundárias (Ferreira, 2020).

Entre os efeitos sobre o sistema hematopoiético, a linfopenia é observada em pacientes infectados por Covid-19, e sua gravidade tem sido associada a pior prognóstico. Assim, sugere-se que a resposta imune desregulada vista na Covid-19 engloba as células T pró-inflamatórias, que, por sua vez, estão fortemente associadas à autoimunidade, bem como a tempestade de citocinas pró-inflamatírias, que são bem características no quadro de infecção aguda. Além disso, o mimetismo entre a 
proteína ANK-1 da membrana dos glóbulos vermelhos e a proteína spike viral foi implicada como outro mecanismo para anemia hemolítica autoimune com Covid-19. (Nesr, et al., 2020). Assim, criaria um potencial reatividade imunológica cruzada entre ANK-1 e proteína spike, contribuindo para desenvolvimento de anemia hemolítica autoimune em pacientes com Covid19 (Renganathan, et al., 2021).

\section{- Lúpus Eritematoso Sistêmico}

A suposta suscetibilidade pode ser explicada através do estresse oxidativo causado por infecções virais, que aumentam o defeito de metilação do DNA na doença de lúpus eritematoso sistêmico (LES), resultando em bastante hipometilação, superexpressão da proteína ACE-2 e maior viremia. Ademais, a desmetilação de genes regulados por interferon, NFкB e citocinas em indivíduos com lúpus pode exacerbar a resposta imune à infecção e elevar os níveis de citocina. Tais fatores facilitam a entrada do vírus no organismo e levam a uma resposta imunológica exacerbada. Paralelamente, há relatos de pacientes que desenvolveram lúpus eritematoso sistêmico após a infecção pelo vírus (Batista, et al. 2021).

Estudo de Zhou et al. (2020), analisou 21 pacientes e os autores chegaram à conclusão de que fenômenos autoimunes existem nas pessoas afetados pela Covid-19. No entanto, o desenvolvimento de doenças reumatológicas, como lúpus eritematoso sistêmico, após a infecção por Sars-CoV-2 não está, atualmente, completamente descrita na literatura. O LES é uma doença inflamatória crônica que pode manifestar-se com quadro clínico diferente, dependendo do paciente. predisposição genética, gatilho ambiental, meio hormonal, interação no desenvolvimento e atividade da doença (Bonometti, et al. 2020).

\section{Conclusão}

Acredita-se que o Covid-19 possua características clínicas semelhantes às doenças autoimunes, pois ambas compartilham grandes reações imunes da patogênese, e que o Sars-CoV-2 pode alterar a autotolerância e gerar respostas autoimunes através da reatividade cruzada com células hospedeiras. No entanto, ficará a cargo da comunidade científica investigar essa possibilidade mais a fundo para validar ou reprovar essa hipótese, haja vista a facilidade em detectar autoanticorpos, corroborando, dessa forma, a constatação de que eles, desencadeados ou não pela Covid-19, são realmente uma ameaça de alteração no sistema imunológico ou se trata apenas de anomalias de pesquisas.

\section{Referências}

Alberti, P., Beretta, S., Piatti, M., Karantzoulis, R., Piatti, M. L., Santoro, P. \& Ferrarese, C. Guillain-Barré syndrome related to COVID-19 Infection. Neurol Neuroimmunol Neuroinflamm, 7 (4), 1-5. https://doi.org/10.1212/NXI.0000000000000741

Batista, B. O., Santos, T. J. F. F. \& Gonçalves, H. M. (2021). Uma análise sobre a relação da doença do coronavírus com lúpus eritematoso sistêmico. Revista Multidisciplinar, 2 (2), https://doi.org/10.51161/rems/1017

Bonometti, R., Sacchi, M. C., Stobbione, P., Lauritano, E. C., Tamiazzo, S., Marchegiani, A., Novara, E., Molinaro, E., Benedetti, I., Massone, L., Bellora, A. \& Boverio, R. O primeiro caso de lúpus eritematoso sistêmico (SLE) desencadeada por infecção COVID-19. European Review for Medical and Pharmacological Sciences, 24 (1), 9695-9697.

Caress, J. B., Costoro, R. J., Simmons, Z., Scelsa, S. N., Lewis, R. A., Ahlawat, A. \& Narayanaswami, P. (2020). COVID-19-associated Guillain-Barré syndrome: The Early pandemic experience. Muscle \& Nerve Wiley, 62 (1), 485-491.

Chan, M., Han, S. C., Kelly, S., Tamini, M., Giglio, B. \& Lewis, A. (2020). Uma série de casos de síndrome de Guillain-Barré após infecção por Covid-19 em Nova York. Neurol Clin Pract. 1-9.

Chang, S. E., Feng, A., Meng, W., Sokratis, A., Apostolidis, A., Greib, S., James, J. \& Utz, P. (2021). New-Onset IgG Autoantibodies in Hospitalized Patients with COVID-19. BMJ, 1-78. https://doi.org/10.1101/2021.01.27.21250559.

Ferreira, H. H. F., Medeiros, L. G. D., Fagundes, R. B. C., Rogério, D. B., Freitas, A. E. F. D. R., Farkatt, I. G., Macedo, C. C. G., Maciel, J. F. R., Junior, F. A. A. E. S. \& Villarim, C. C. (2020). Anemia hemolítica autoimune secundária à infecção por Sars-CoV-2 e suas características: revisão de literatura. Hematol Transfus Cell Ther, 42 (2), 32-33.

Gupta, A., Paliwal, V. K. \& Garg, R. K. (2020). Is COVID-19-related Guillain-Barré Syndrome Different? Brain, Behavior, and Immunity, 87 (1), 177-178. https://doi.org/10.1016/j.bbi.2020.05.051 
Huang, C., Wang, Y., Li, X., Ren, L., Zhao, J. \& Hu Y. (2020). Características clínicas dos pacientes infectado com novo coronavírus 2019 em Wuhan, China. The Lancet. 395 (10223): 497-506. https://doi.org/10.1016/S0140-6736(20)30183-5.

Magagnoli, J., Narendran, S., Pereira, F., Crummings, T., Hardin, J. W., Pharm, S. S. S. \& Ambati, J. (2020). Outcomes of hydroxychloroquine usage in United States veterans hospitalized with Covid-19. MedRxiv. Preprint, 1- 27. https://doi.org/10.1101/2020.04.16.20065920

Mao, L., Wang, M., Chen, S., He, Q., Chang, J. \& Hong C. (2020). Manifestações neurológicas de pacientes hospitalizados com COVID-19 em Wuhan, China: estudo retrospectivo de série de casos. JAMA Neurol., 77 (6), 683-690.

Nesr, G., Kosky, R., Foldes, D. \& Kagdi, H. (2020). Autoimmune haemolytic anaemia and a marked rise in the lymphocyte count associated with COVID-19 in a patient with treatment-na€ıve chronic lymphocytic leukaemia: a case report. British Journal of Haematology, 190 (1), $322-328$.

Rana, S., Lima, A. A., Chandra, R., Valeriano, J., Desai, T., Freiberg, W. \& Small, G. (2020). Novo Coronavírus (COVID-19) Associado a Síndrome de Guillain-Barre: relato de caso. J Clin Neuromusc Dis, 21 (4), 240-242.

Renganathan V., Dhanalakshmi, K. S., Nanda, A. \& Gopinath, R. (2021). Severe haemolytic anaemia in COVID 19- A rare manifestation. Indian J Anaesth, $65(1), 489-490$.

Rumeileh, S. A., Abdelhak, A., Foschi, M., Tumani, H. \& Otto, M. (2021). Espectro da síndrome de Guillain-Barré associado a COVID - 19: uma revisão sistemática atualizada de 73 casos. Journal of Neurology, 268 (1), 1133-1170. https://doi.org/10.1007/s00415-020-10124-X

Sedaghat, Z. \& Karimi, N. (2020). Síndrome de Guillain Barre associada à infecção por COVID-19: um relato de caso. Journal of Clinical Neuroscience, 76 (1), 233-235.

Toscano G., Palmerini F., Ravaglia S., Ruiz L., Invernizzi P., Cuzzoni M. G., Franciotta D., Baldanti F., Daturi R., Postorino P., \& Cavallini A. (2020). Síndrome de Guillain Barré Associado ao SARS-CoV-2. New England Journal of Medicine, 382 (26), 2574-2576.

Zhou, Y., Han, T., Chen, J., Zhao, C. \& Li, J. (2020). Clínica e Características Autoimunes de Graves e Críticos Casos cal de COVID-19. Clin Transl Sci, 13 (6), 1077-1086. 